\title{
SUSTENTABILIDADE E MODA: \\ UM ESTUDO BIBLIOMÉTRICO DOS ANAIS DO COLÓQUIO DE MODA
}

\author{
SUSTAINABILITY AND FASHION: A BIBLIOMETRIC STUDY \\ OF THE ANNOUNCES OF THE "COLÓQUIO DE MODA"
}

\section{Carlos Viana da Silva', Carla Pantoja Giuliano²}

\author{
Recebido em: 08 de maio de 2017 \\ Aprovado em: 19 de junho de 2017 \\ Sistema de Avaliação: Double Blind Review \\ RCO | a. 9 | v. 2 | p. $92-104$ | jul./dez. 2017
}

\begin{abstract}
RESUMO
O presente artigo é o resultado de estudos, análises e considerações buscando determinar a relação entre o design, sustentabilidade e o design de moda, apresentando um estudo bibliométrico das publicações dos anais do maior evento sobre Moda no Brasil, o Colóquio de Moda. Apresenta reflexões sobre possíveis caminhos a serem seguidos em busca de uma sociedade mais sustentável, no âmbito ecológico, social e econômico. Como estrutura, essa estudo bibliométrico apresenta inicialmente o referencial teórico acerca do design sustentável. Seguindo aborda o método utilizado para o desenovlvimento desse artigo, e por fim traz as análises, resultados e considerações. Com este trabalho, foi possível perceber que será preciso rever o atual comportamento político econômico social, para que seja possível alcançarmos níveis melhores de sustentabilidade e qualidade de vida, exigindo uma considerável habilidade de design em projetar e organizar visões de um sistema sociotécnico sustentável em um sistema coerente de produtos e serviços.
\end{abstract}

Palavras-chave: Design. Sustentabilidade. Moda. Bibliometria.

\begin{abstract}
This article is the result of studies, analyzes and considerations seeking to determine the relationship between design, sustainability and fashion design, presenting a bibliometric study of the annals of the largest event on fashion in Brazil, the 'Colóquio de Moda'. It presents reflections on possible paths to be followed in search of a more sustainable society, in the ecological, social and economic sphere. As a structure, this bibliometric study initially presents the theoretical reference about sustainable design. Following approaches the method used for the development of this study, and finally brings the analyzes, results and considerations. This work reveals that it will be necessary to review the current social and political economic behavior so that it is possible to achieve better levels of sustainability and quality of life, requiring a considerable design skill in designing and organizing visions of a sustainable sociotechnical system in a logical system of products and services.
\end{abstract}

Keywords: Design. Sustainability. Fashion. Bibliometrics.

\section{INTRODUÇÃO}

A sustentabilidade é um tema que gradualmente vem ganhando evidência e sendo pesquisado com maior destaque no Brasil (e no mundo) nos últimos anos. Boa parte dessa crescente se deve ao fato

\footnotetext{
${ }^{1}$ Mestre em Design pelo Centro Universitário Ritter dos Reis (Porto Alegre/Brasil). E-mail: alemao.viana@gmail.com.

${ }^{2}$ Doutora em Desenho Industrial pelo Politecnico di Milano (Milão/Itália). Professora no Centro Universitário Ritter dos Reis (Porto Alegre/Brasil). E-mail: carla_giuliano@uniritter.edu.br.
} 
de as informações sobre os problemas ambientais, sociais e econômicos estarem mais facilmente ao alcance das pessoas.

Tendo em vista esse crescimento sobre o tema e a amplitude de áreas que se relacionam com a sustentabilidade, pode-se considerar o campo do Design de Moda como um segmento importante para inserção de tais estudos. Levando em conta essas considerações, a presente pesquisa busca apresentar uma análise bibliométrica das publicações sobre Sustentabilidade e Moda no país. Para tal, optou-se por realizar o estudo no maior congresso científico do Brasil na área da Moda, o Colóquio de Moda. O principal objetivo desse evento é promover e estimular a troca de conhecimentos acerca do estado da arte, ciência e da tecnologia, dadas a partir da produção científica nacional e internacional no campo da Moda abrangendo também suas inter-relações (COLÓQUIO DE MODA, 2017).

O evento escolhido ocorre anualmente desde 2005 e abrangendo as áreas do Design, Moda, História, Artes, Sociologia, Economia, Psicologia, Marketing, Jornalismo, Publicidade e Administração, consolidou-se como "o maior espaço de intercâmbio acadêmico-científico entre pesquisadores, líderes e membros de grupos de pesquisa, docentes e estudantes oriundos dos Programas de Pós-Graduação e dos cursos de Graduação do país" (COLÓQUIO DE MODA, 2017).

Esse estudo bibliométrico analisou todos os artigos publicados e disponíveis no site do evento, compreendendo os anos de 2005 a 2016 e está estruturado da seguinte maneira: primeiramente apresenta-se o referencial teórico sobre sustentabilidade e sua inter-relação com as questões ambientais, sociais e econômicas, buscando elucidar tais conceitos. Dando sequência apresenta-se o método utilizado para realizar essa pesquisa. Por fim encontram-se os resultados, análises e as considerações finais.

O presente cenário social - meados da segunda década do século XXI - retrata uma cultura estabelecida sob práticas de consumo excessivo e difusas em diferentes classes sócias. Essa época, exposta como modernidade líquida (ou de risco) é marcada por sensíveis transições sociais - uma fase em que as ameaças relacionadas à sustentabilidade (riscos ambientais, sociais e econômicos) estão propensas a escaparem do controle a qualquer momento. (BAUMAN, 2009; BECK, 1997; FRY, 2011; MANZINI; VEZZOLI, 2002). Nesse contexto, caracterizado por incertezas constantes, o grande volume de lixo gerado - em consequência ao consumo excessivo - é o subproduto de maior profusão.

De acordo com Forty (2007, p. 13), "o principal objetivo da produção de artefatos, um processo no qual o design faz parte, é dar lucro para o fabricante". O autor sugere que qualquer grau de imaginação artística utilizado no desenvolvimento de produtos é executado para tornar os produtos vendáveis e lucrativos, e pouco tem a ver com dar expressão à criatividade e à imaginação do projetista. Sob tal condição, é de suma importância que os designers contemporâneos assumam cargos estratégicos nas relações entre as indústrias e a sociedade. Esse profissional inovador, progressivamente carecerá trabalhar de um modo político pedagógico, inteirando consumidores, clientes e a sociedade com relação à relevância dos problemas ambientais e sociais, projetando e apresentando alternativas inovadoras orientadas pelas necessidades fundamentais dos seres humanos.

Segundo Papanek (1997, p. 14), o “[...] designer tem sido sempre [...] um professor, estando em posição de informar e influenciar o cliente. Com a atual confusão ambiental é ainda mais importante que ajudemos a orientar a intervenção do design, de modo que seja natural e humana".

Conforme Cardoso (2008), a divergência entre consumo e degradação ambiental não é um problema superado e nem uma postura de alarmismo ou "ecochatice". Não restam dúvidas de que esse modelo estruturado em um consumo intenso e generalizado, com a ideia da prosperidade pela ampliação contínua da produção e das vendas torna-se insustentável em longo prazo. 
Segundo Chick e Micklethwaite (2011, p. 78, tradução nossa), precisa-se "olhar para o futuro, aprendendo com o passado. Um comprometer-se com o 'progresso' humano pode ser perigoso se esquecermos de aprender com nosso passado". Conforme os autores, o vocábulo 'sustentabilidade' abrange um síncrono complexo de ideias, englobando praticamente todos os aspectos inerentes a consciência humana e às responsabilidades sob os aspectos ecológicos, sociais e econômicos. Com isso torna-se difícil definir a sustentabilidade em poucas palavras. Como consequência, muitas vezes pode ser caótico para os designers e projetistas (e todos os demais trabalhadores envolvidos nos procedimentos de produção de artefatos) encontrarem as melhores formas de agir em busca de uma melhor prática sustentável. A sustentabilidade é, em algumas vezes, minimizada aos aspectos individuais de cada produção, o que pode ser perigoso se distrair as atenções das questões mais abrangentes. Corre-se o risco de colocar o foco em questões amplamente visíveis (como os materiais poluentes, por exemplo) e não abordar os impactos ambientais e sociais globais dos nossos estilos de vida, organizações e vizinhança.

O design é uma área destinada a materializar ideias, viabilizar soluções, gerar alternativas, e assim como no discurso político, nos últimos vinte anos, termos como responsabilidade ambiental, inclusão social e sustentabilidade entraram em voga (CARDOSO, 2013). Os designers, por fazerem parte do processo decisório sobre as características produtivas, acabam por integrar a problemática relacionada ao consumo e a sustentabilidade no desenvolvimento de suas atividades.

Embora algumas vezes a expressão desenvolvimento sustentável (ou sustentabilidade) seja confundida com atitudes relacionadas à proteção da natureza, ou aos cuidados ambientais, este conceito abrange outras esferas - social e econômica - que se inter-relacionam na medida em que se compreende que os efeitos de 'nossas' ações, sejam compatíveis com a permanência de uma vida humana autêntica sobre a terra (JONAS, 1995).

Poucas pessoas no mundo podem continuar sem consciência do fato de que suas atividades locais são influenciadas, e às vezes até determinadas por acontecimentos ou organismos distantes [...]. As ações cotidianas de um indivíduo produzem conseqüências globais [...]. Esta extraordinária - e acelerada - relação entre as decisões do dia-a-dia e os resultados globais, juntamente com o seu reverso, a influência das ordens globais sobre a vida individual, compõem o principal tema da nova agenda. As conexões envolvidas são freqüentemente muito próximas. Coletividades e agrupamentos intermediários de todos os tipos, incluindo o estado, não desaparecem em conseqüência disso, mas realmente tendem a ser reorganizados ou reformulados (GIDDENS, 1997, p.75).

Talvez o fato do senso comum não compreender a simbiose entre o homem e a natureza tenha contribuído para agravar os problemas ambientais que comprometeram as sociedades antigas, acrescidos dos problemas das sociedades modernas como as mudanças climáticas causadas pelo homem, acúmulo de produtos tóxicos no ambiente natural; escassez de energia e a diminuição da capacidade fotossintética do planeta (CHICK; MICKLETHWAITE, 2011; DIAMOND, 2011). Conforme Mariotti (2013), as relações entre o individualismo humano e a ideia de sustentabilidade são muitas vezes conflituosas, mas é fundamental compreender que nem sempre o individualismo prevaleceu em todas as épocas e culturas.

Nos últimos anos as informações sobre o desenvolvimento sustentável cresceram consideravelmente, mas este assunto está intimamente ligado ao comportamento humano. Um tema como a sustentabilidade deve ser introduzido gradativamente no cotidiano das pessoas. De acordo com Camargo (2003), essas informações devem estar presentes dentro da sala de aula, para que as novas gerações de crianças possam exercer ações sustentáveis com maior naturalidade. 
Barros (2010, p. 4) defende que se deve levar em conta que o maior problema na educação ambiental é a falta de professores capacitados para trabalhar em sala de aula a importância dos problemas ambientais que o mundo vem enfrentando:

\begin{abstract}
A relação entre meio ambiente e educação para a cidadania assume um papel desafiador, os desafios para os educadores ambientais são, de um lado, o resgate e o desenvolvimento de valores e comportamentos (confiança, respeito mútuo, responsabilidade, compromisso, solidariedade e iniciativa) e de outro, o estímulo a uma visão global e crítica das questões ambientais e a promoção de um enfoque interdisciplinar que resgate e construa saberes. Ou seja, o grande desafio é quebrar uma cultura consumista acomodada, e tentar orientar a mesma para novos hábitos ecologicamente corretos.
\end{abstract}

A educação para a sustentabilidade permitirá pelos seus pressupostos básicos, uma nova interação criadora que redefina o tipo de pessoa que se queira formar e os cenários futuros que se desejam construir para a humanidade, em função do desenvolvimento de uma nova racionalidade ambiental (MEDINA; SANTOS, 2000).

\title{
2 SUSTENTABILIDADE
}

O termo "desenvolvimento sustentável” teve sua primeira utilização pública em agosto de 1979, no Simpósio das Nações Unidas sobre as inter-relações entre recursos, ambiente e desenvolvimento (VEIGA, 2007, p.61). Apesar disso, segundo Margolin (1989), é possível identificar, nos anos 70, designers - como Dieter Rams e Vitor Papanek - entre os vanguardistas a perceberem que a sustentabilidade deveria ser um dos principais critérios norteadores de um bom projeto.

Em uma era de linha de produção, em que tudo tem que ser planejado e projetado, o design tornou-se a ferramenta mais poderosa que o homem usa para configurar suas ferramentas e o meio ambiente (e, por extensão, a sociedade e ele próprio). Isto exige do designer uma responsabilidade moral e social. Também requer profissionais de design com uma maior compreensão das pessoas, e do público um conhecimento mais amplo sobre o processo de design (PAPANEK, 1971, p. 12, tradução nossa).

Manzini e Vezzoli (2002) sugerem que a sustentabilidade ambiental se refere às condições sistêmicas segundo as quais, em nível regional e planetário, as atividades humanas não devam interferir nos ciclos naturais em que se baseiam tudo o que a resiliência do planeta permite e, ao mesmo tempo, não deveriam empobrecer seu capital natural. Mencionam ainda que, para que seja possível considerar as atitudes humanas como sustentáveis, estas devem atender aos seguintes requisitos:

a) Basear-se fundamentalmente em recursos renováveis, garantindo, ao mesmo tempo, aperfeiçoar o emprego dos recursos não renováveis (compreendidos como ar, água e o território);

b) Não acumular quantidades de lixo que o ecossistema não seja capaz de reutilizar;

c) Assegurar que as comunidades permaneçam dentro dos limites de seus espaços ambientais, bem como possam efetivamente gozar dos espaços ambientais aos quais potencialmente têm direitos.

A fim de fundamentar-se em recursos renováveis, uma economia sustentável necessita economizar energia, seja elétrica, eólica ou humana. Uma cidade que proporciona um sistema de transporte coletivo eficiente, rápido e seguro, por exemplo, há economia de energia humana. Manzini e Vezzoli (2002, p. 28) esclarecem que “[...] material e energia tem não só um grande custo econômico, mas também um grande custo ambiental". 
Manzini (2008) afirma, sob o ponto de vista da inovação social para a sustentabilidade que

[...] as inovações sociais de base na vida cotidiana (as comunidades criativas), que indicam como, às vezes, as habilidades difusas de design são capazes de criar modos de ser e de fazer ao mesmo tempo criativos e colaborativos, considerados também como passos promissores rumo à sustentabilidade (MANZINI, 2008. p. 17).

Segundo o autor, um fator de transformação da sociedade contemporânea é o fato de que os limites da Terra tornaram-se mais evidentes. Considerando o sistema cultural e operacional da sociedade industrial como um todo, o tema dos limites não está simplesmente relacionado com as questões ambientais, mas em que forma de desenvolvimento não comprometeria o bem-estar, ou todas as vidas, das futuras gerações (MANZINI, 2008).

Bosselmann (2009) propõe que o atual entendimento da sociedade sobre o assunto está estruturado em um sentido fraco, no qual a sustentabilidade é apenas uma meta - o ponto central de encontro entre os três pilares contemplados pelo desenvolvimento sustentável, conforme ilustra a Figura 1.

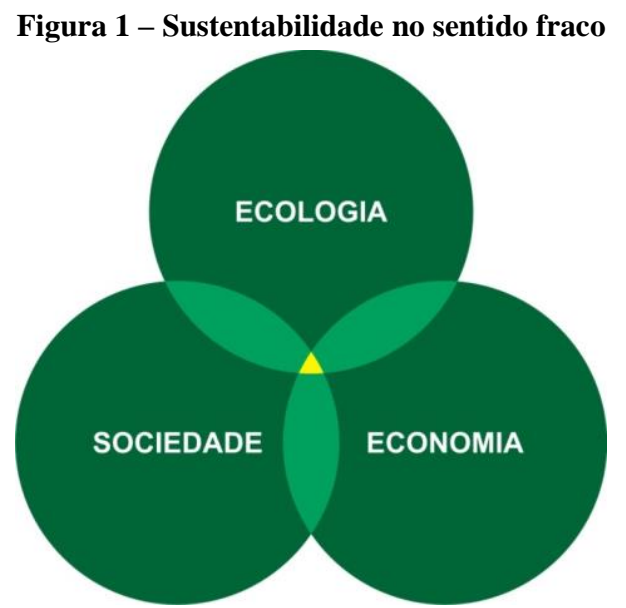

Fonte: Desenvolvido pelos autores com base em Bosselmann (2009)

Por outro lado, o mesmo autor acredita na transição para o desenvolvimento sustentável no sentido forte, no qual a esfera ecológica, que condiciona todas as formas de vida na Terra, é limitante das atividades referente à esfera social, e esta por fim aparece como fronteira para as ações provenientes da esfera econômica. Esse conceito está ilustrado na Figura 2.

Figura 2 - Sustentabilidade no sentido forte

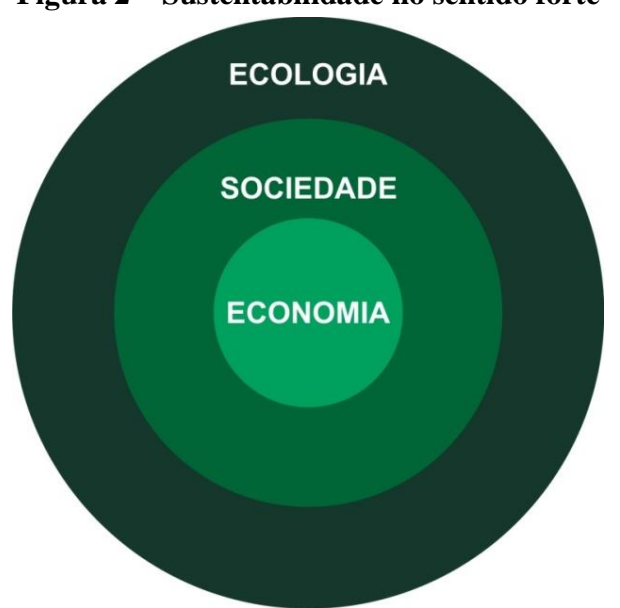

Fonte: Desenvolvido pelos autores com base em Bosselmann (2009) 
Vezzoli (2010) defende que sustentabilidade se faz com equidade e coesão social. O princípio da equidade propõe que todas as pessoas, em uma distribuição justa de recursos, tenham direito ao mesmo espaço ambiental. Em outras palavras, a níveis equivalentes de satisfação, oportunidade de acesso e disponibilidade de recursos naturais globais. Seguindo esse pressuposto, o autor propõe requisitos e diretrizes de design de sistemas para a equidade e coesão social, tais como aumento da empregabilidade e melhores condições de trabalho; aumento da equidade e da justiça em relação aos atores envolvidos; promoção do consumo responsável e sustentável; favorecimento e integração das pessoas com necessidades especiais e marginalizadas; melhoraria da coesão social e o incentivo do uso e a valorização dos recursos locais.

Para que se configure um desenvolvimento sustentável de fato, é necessário que a sociedade passe por um período de transição/transformação. Vários autores acreditam que essa transição já começou, e o que definirá o grau de transformação será o nível de informação da população. Manzini e Vezzoli (2002) acreditam haver dois caminhos que podem nortear essa transição rumo à sustentabilidade: o caminho "traumático", no qual o processo será forçado por fenômenos e efeitos catastróficos; e o caminho indolor, no qual essa transição se dará por uma escolha consciente e prudente.

Vale salientar que essa possível transição em busca de uma sociedade mais preocupada com questões sustentáveis nada se parece com um caminho simples e harmonioso, e sim um processo de aprendizagem social, no qual os seres humanos, gradualmente, aprenderão através de seus erros e contradições, consumindo menos e regenerando a qualidade do ecossistema global e dos contextos locais. Esta tarefa irá implicar uma considerável habilidade de design, projetando e organizando visões de um sistema sociotécnico sustentável num sistema coerente de produtos e serviços regenerativos (MANZINI, 2008).

Para um sucinto entendimento do estado da arte do tema "design para a sustentabilidade", de uma forma geral (e em uma perspectiva europeia), foram mapeadas quatro dimensões em um diagrama que destaca, de um lado, o nível de consolidação científica (derivado de resultados de pesquisa em design) e, de outro, sua disseminação no ambiente profissional (e nas IES) (VEZZOLI, 2010, p. 56). [Ilustrado na Figura 3].

Figura 3 - Estado da arte design para sustentabilidade

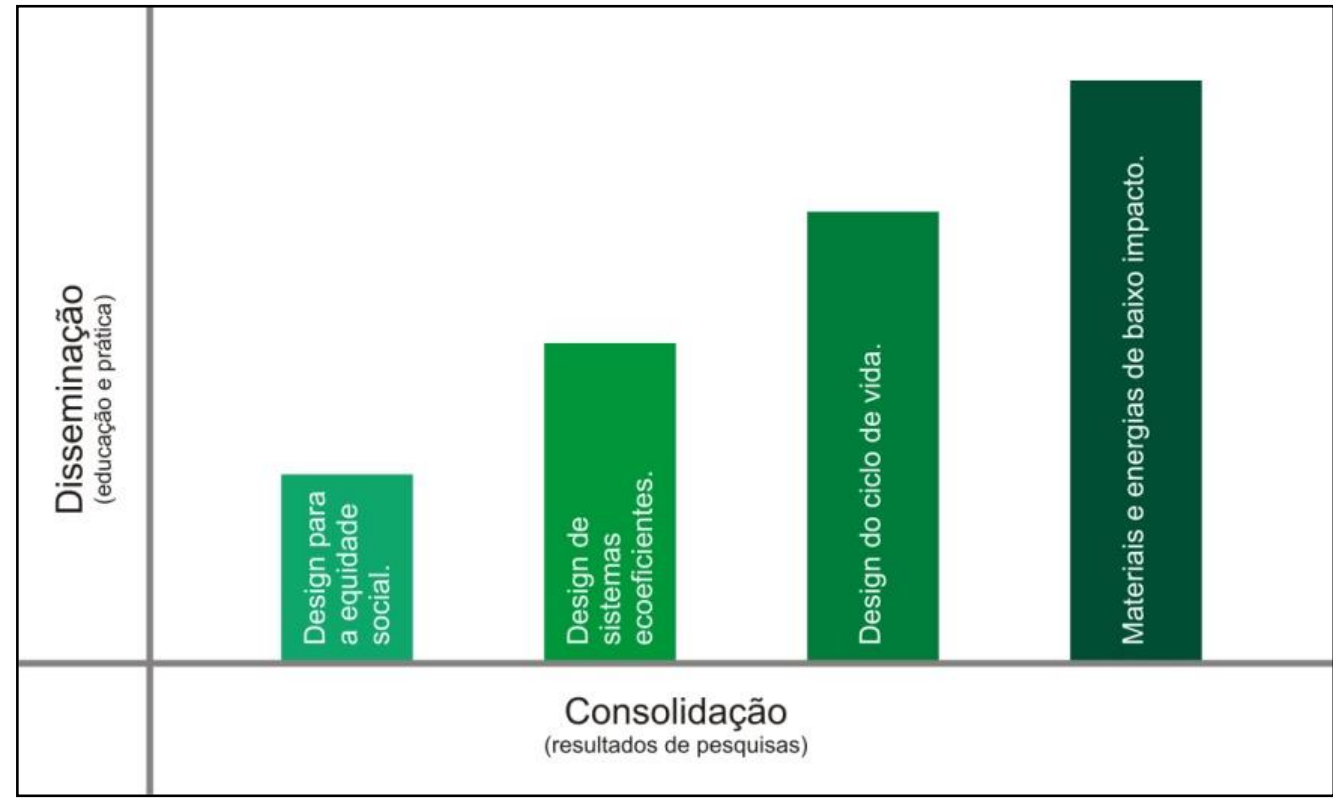

Fonte: Desenvolvido pelos autores com base em Vezzoli (2010) 
A consolidação, disseminação e o entendimento das demais dimensões relacionadas ao design para o desenvolvimento sustentável confirmam o deslocamento da ênfase dos trabalhos de controles end-of-pipe ${ }^{3}$, das ações de reparação de danos e dos atos de prevenção, para as preocupações com a dimensão sociocultural, onde o designer deve estabelecer conexões entre o mundo da produção e o do consumo (usuário) (VEZZOLI, 2010).

Compreendendo ainda que “[...] o crescimento econômico será inexoravelmente inviabilizado por falta dos recursos naturais [...]” (VEIGA, 2013. p. 101), evidencia-se que algumas mudanças nos atuais padrões sociais devam acontecer. Esta mudança, conforme Fry (2011, p. 252, tradução nossa), "exige um processo de decisão e ação diretiva que traga os dois imperativos de liberdade e futuro juntos para formar uma unidade indissolúvel".

[...] essa nova economia poderia propor mudanças de direção, como, em sua forma mais simples, a criação de produtos de longa duração trocados por um valor econômico e cultural muito maior. [...] Esses produtos iriam transformar a maneira como as coisas são vistas, usadas e valorizadas (FRY, 2011. p. 65, tradução nossa).

Mudar a perspectiva do interesse das coisas para os resultados, imaginar soluções alternativas, avaliar e comparar as várias soluções alternativas e desenvolver as soluções mais adequadas representam alguns dos desafios que o designer contemporâneo precisa enfrentar, caso almeje ampliar e efetivar os conceitos do desenvolvimento sustentável (MANZINI 2008).

Em essência, conforme acredita Fry (2011, p. 65, tradução nossa), o objetivo geral desta transição em busca de um cenário sustentável, deve considerar reconfigurar a relação entre a produção e o consumo, tornando a produção mais gratificante, atraente e digna, fazendo com o que seja consumido, de fato seja efetivamente consumido ou o mais duradouro possível. Desenvolver serviços com maior relevância, diversidade de funções sociais e econômicas. Uma economia centrada em um grande desenvolvimento de formas de produções culturais, com o objetivo de alterar o equilíbrio entre produção e consumo cultural. Essas atividades, ao invés de serem práticas participativas de minorias, seriam posicionadas como elementos chave da vida cotidiana. Assim como a música, a dança, as artes visuais, o artesanato, entre outros, não seriam mais vistos apenas como um meio de prazer, mas como uma base para criar e explorar novas formas de ver e aprender.

Mesmo existindo apontamentos sobre o desenvolvimento de inovações sustentáveis, vale salientar que pode não ser fácil inovar - pois se deve romper com as barreiras orçamentárias e, principalmente, culturais, entre outras questões, para que as inovações gerem produtos e serviços com caráter sustentável de sentido forte. Fry (2011, tradução nossa) considera existir três principais fundamentos a serem seguidos para que possivelmente se alcancem avanços em relação à sustentabilidade:

1) A criação de, e o movimento para, um novo paradigma econômico que abandona o conceito de crescimento quantitativo contínuo;

2) A adaptação do mundo material de consumo que foi estabelecido concomitante com o desenvolvimento industrial (o alcance real desta tarefa é enorme e atualmente obscurecido pela criação contínua e crescente de artefatos, incluindo os ditos produtos amigos do meio ambiente e as 'coisas verdes');

\footnotetext{
${ }^{3}$ End-of-pipe é o termo designado para as tecnologias utilizadas buscando tratar a poluição gerada em algum processo produtivo, com a incorporação de novos equipamentos nos pontos de descarga de poluentes (BARBIERI, 2004).
} 
3) O reconhecimento de que a atual estrutura insustentável se tornou elementar para a existência e continuidade do ser humano modernizado.

Embora o avanço tecnológico traga inúmeras melhorias para o bem-estar do homem, parece não dar conta de dois outros fatores que mais contribuem para o impacto ambiental das atividades humanas, como o tamanho da população e seu nível de afluência, em outras palavras, o aumento populacional e dos níveis de consumo (VEIGA, 2013).

Frente à complexidade das questões relacionadas ao desenvolvimento sustentável e o atual comportamento social, vislumbra-se uma oportunidade em pesquisar novas formas para lidar com os problemas apresentados, incluindo novos modelos econômicos, estendendo os limites do design.

Levar o design além dos limites usuais significa que será necessário um novo tipo de pensamento e prática do design, incluindo novas formas de ensinar, com valores e objetivos adaptados para este cenário complexo contemporâneo. De acordo com Fry (2011, tradução nossa), existem três possíveis movimentos para que se possa alcançar tal objetivo:

1) Ampliar o âmbito do design para além do âmbito do discurso existente;

2) Reconhecer que a humanidade em geral está entrando em um terceiro momento de habitação mundial, a era da instabilidade;

3) Levar o design além da linha desenhada sobre as políticas institucionais existentes.

Vale ressaltar que essa ideia de sustentabilidade irrestrita não implica qualquer tipo de retorno da sociedade à natureza, e sim o reconhecimento e o engajamento com as propriedades que definem todas as relações sociais, diminuindo o consumo excessivo dos produtos (materiais) artificiais que agora já estão naturalizados, infundindo e poluindo o planeta. Um processo de decisão e ação diretiva, com profissionais que apresentem uma maior compreensão das pessoas, unindo políticos, designers, universidades, escolas e a sociedade como um todo, trazendo os imperativos de liberdade e futuro juntos para formar uma unidade indissolúvel.

\section{MÉTODO}

O presente estudo é de caráter quantitativo e como método de coleta de dados utilizou-se da Bibliometria com o objetivo de selecionar e analisar artigos do Colóquio de Moda que apresentavam o termo "Sustentabilidade" em seu conteúdo. A pesquisa bibliométrica, é determinada como um instrumento estatístico para medir ou avaliar através do mapeamento, gerando indicadores de tratamento e gestão da informação. A bibliometria consiste na utilização de técnicas matemáticas e estatísticas para apresentar aspectos da literatura e de outros meios de comunicação (ARAÚJO, 2006).

Essa técnica tem sido utilizada com o objetivo da métrica de citações nas mais diversas áreas do conhecimento e segundo Lazzarotti, Dalfovo e Hoff (2011), a utilização dos resultados encontrados permite descrever e analisar a trajetória do desenvolvimento das produções científicas.

O procedimento foi realizado nas seguintes etapas:

1) Estabelecimento da temática a ser pesquisada - Sustentabilidade e Moda;

2) Escolha do evento a ser estudado;

3) Definição dos artigos a serem analisados;

4) Determinação do termo a ser pesquisado nos artigos - sustentabilidade;

5) Pesquisa digital com o termo escolhido;

6) Agrupamento dos dados. 
Com o objetivo de explicitar a produção acadêmica sobre Sustentabilidade e Moda, na etapa inicial pesquisou-se sobre os conceitos relativos conforme apresentado previamente. Com isso foi possível perceber a importância entre a relação de tais assuntos com a Moda, incitando o desenvolvimento desse estudo para detectar o quanto está sendo pesquisado no Brasil.

Após a definição do evento a ser estudado, partiu-se para a seleção dos artigos analisados. Optouse por realizar o estudo somente com os artigos publicados na seção "Grupos de Trabalho (GT)" e "Comunicação Oral (CO)". Por se tratarem trabalhos de iniciação científica, os artigos incluídos na categoria "Pôster" foram excluídos da pesquisa.

\section{RESULTADOS E ANÁLISE}

Foram selecionados 1997 artigos que estavam disponíveis de forma eletrônica nos Anais do Colóquio de Moda. De todas as edições do evento realizadas, apenas os artigos referentes ao $5^{\circ}$ Colóquio de Moda, do ano de 2009, não estavam disponíveis on-line, ficando de fora desse estudo.

Realizou-se então a pesquisa digital para encontrar os artigos que continham a expressão “sustentabilidade" em seu conteúdo. Foram encontrados 305 artigos, distribuídos pelos anos e edições conforme representado na Figura 4.

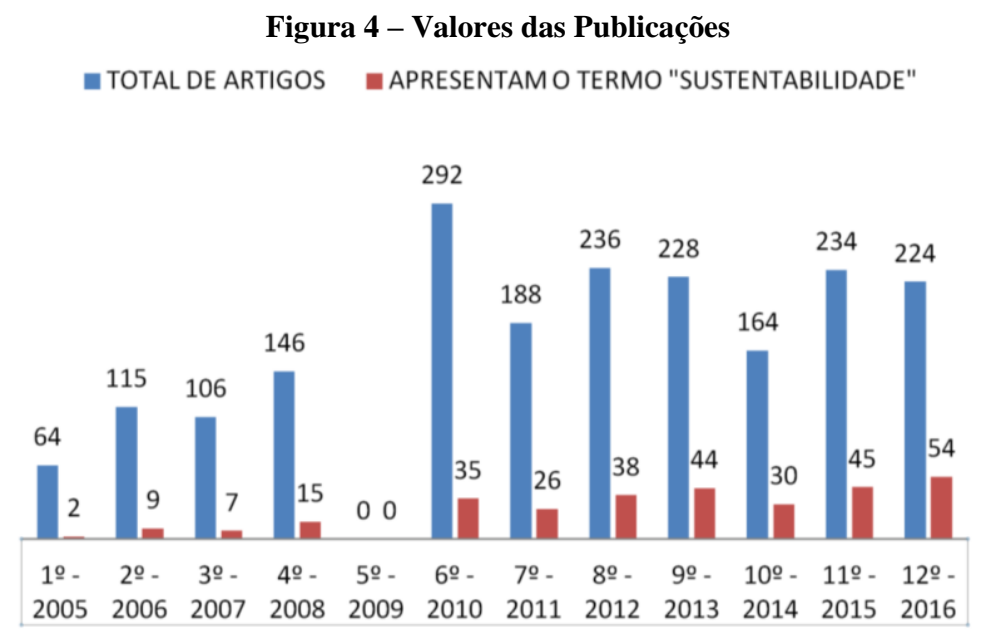

Fonte: Desenvolvido pelos autores

Ao analisar os dados obtidos é possível perceber que os estudos sobre moda e sustentabilidade foram aumentando com o passar do tempo. Embora apresente uma queda no número de artigos publicados entre os anos 2006 e 2007, entre 2010 e 2011, e entre 2013 e 2014, ao converter esses dados na porcentagem que estes representam do total de trabalhos, pode-se visualizar melhor o crescimento do nível do interesse sobre o tema, conforme pode ser observado na Figura 5. 
Figura 5 - Percentagem Representada

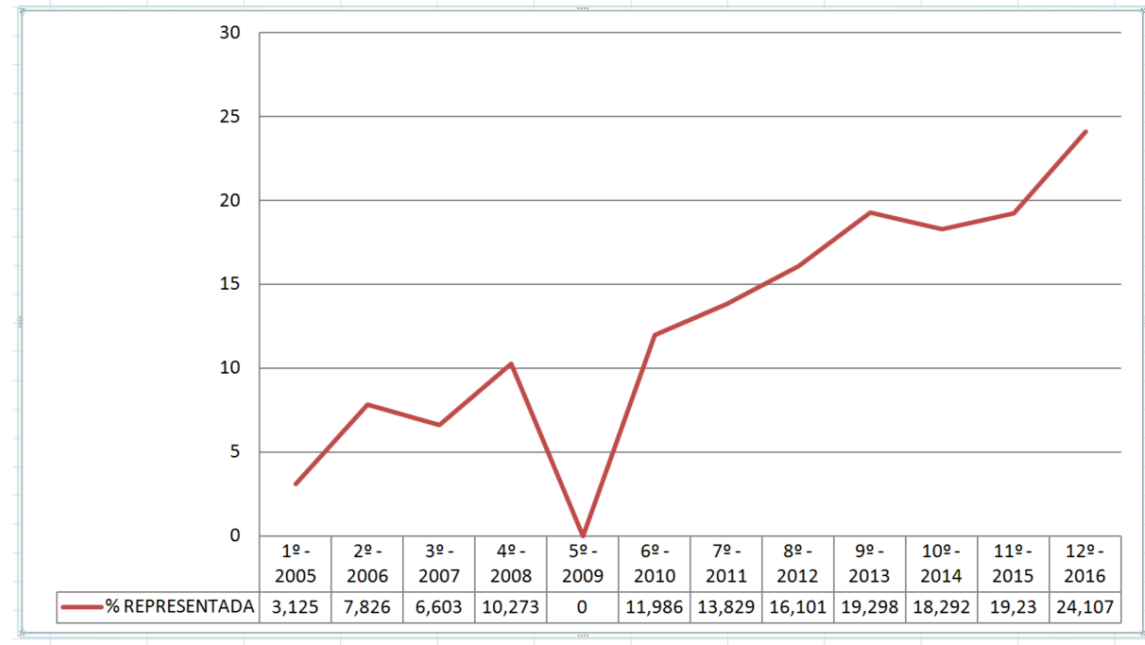

Fonte: Desenvolvido pelos autores

Observa-se que entre os anos de 2006 e 2007 houve uma queda de 1,223\% do total de artigos que apresentavam o termo sustentabilidade, assim como entre os anos de 2013 e 2014 uma queda de 1,006\%.

Durante a pesquisa bibliométrica foi possível perceber que, após a quarta edição do evento, quando os artigos que continham a palavra sustentabilidade em seu conteúdo ultrapassara $10 \%$ do total dos trabalhos publicados, o comitê organizador do Colóquio de Moda optou por separar as pesquisas em seções temáticas, criando assim um grupo específico para publicações sobre "Moda e Sustentabilidade".

Dentre os 305 artigos que apresentavam o termo sustentabilidade foi possível identificar pesquisas pautadas com diversas temáticas relacionadas ao desenvolvimento sustentável. Sobre os aspectos ambientais por exemplo, destaca-se o artigo apresentado no segundo Colóquio de Moda intitulado "Projeto Transforma: Uma Região Sustentável", que apresenta uma alternativa para a diminuição da poluição ambiental com base no reaproveitamento de materiais. Abordando aspectos relacionados à esfera social identificou-se, dentre outros, o trabalho "Moda, Artesanato e Tecnologia: Sustentabilidade e Benefícios", em que a pesquisadora descreve a experiência de um projeto piloto com ações socioeducativas e culturais em uma comunidade local, também publicado na segunda edição do evento. Trazendo um olhar sob os aspectos econômicos, o artigo "A Roda de Negócio da Moda Pernambucana como instrumento de competitividade do APL de confecção do Agreste Pernambucano", apresentado no ano de 2010 ( $6^{a}$ edição do Colóquio de Moda) traz uma reflexão sobre os benefícios da Rodada de Negócios da Moda Pernambucana como um diferencial estratégico competitivo.

Também foi possível identificar com esse estudo bibliométrico trabalhos relacionados com as temáticas propostas por Vezzoli (2010) em sua comparação entre consolidação e disseminação de determinados conteúdos ligados ao design sustentável. Sobre o tema "Materiais e energias de baixo impacto", por exemplo, destaca-se o artigo "Do pneu que não roda mais à uma mulher vestida para rodar", publicado na segunda edição do evento, aborda o uso de câmaras de ar e pneus reaproveitados para um design de moda sustentável. Apresentado conteúdo relacionado com o tema "Design do ciclo de vida", evidencia-se o trabalho da décima primeira edição do evento, intitulado "Upcycling: uma nova perspectiva para os produtos de moda" em que o autor traz uma reflexão sobre o impacto da redução do ciclo de vida dos produtos de moda. Trazendo questões relacionadas à temática "Design de sistemas ecoeficientes" foi possível identificar, dentre outros, a pesquisa apresentada em 2015 ( $11^{\circ}$ Colóquio de Moda) com o título "Adequação dos processos de estamparia nas etapas produtivas de produtos de moda 
e vestuário". Relacionado com o tema "Design para a equidade social", destaca-se a pesquisa "Cooperativa de bordadeiras: um relato de experiência envolvendo tecnologia social" que apresenta o trabalho de uma cooperativa local com ênfase na inclusão social, publicado na sexta edição do Colóquio de Moda no ano de 2010.

Além das questões propostas por Bosselmann (2009) e Vezzoli (2010), também foram identificadas pesquisas de caráter reflexivo, como por exemplo o trabalho "O Papel do Designer de moda no Século XXI” ( $\left({ }^{\circ}\right.$ Colóquio de Moda - 2006) em que são apresentadas reflexões sobre os atuais métodos utilizados pelos projetos de moda. Ou ainda pesquisas em que são discutidas questões ligadas ao consumo excessivo, ilustrado pelo artigo "O novo consumidor de moda e a Sustentabilidade" que apresenta considerações sobre o consumidor e o consumo efêmero.

\section{CONSIDERAÇÕES FINAIS}

Evidencia-se com esse estudo que, embora tenha alguma oscilação no crescimento sobre o interesse entre as áreas estudadas, existe uma tendência de expansão nas pesquisas sobre moda e sustentabilidade.

Frente ao contexto insustentável em que a maioria das comunidades se encontra, torna-se axiomático considerar requisitos ambientais, sociais e econômicos durante as fases de projetação, principalmente nas etapas inicias em que se determinam os requistos projetuais. É necessária a percepção dos profissionais criativos para projetarem e desenvolverem produtos com menor impacto ambiental, maior relevância social e com valor econômico agregado que seja, ao mesmo tempo, justo e satisfatório.

Para alcançar tais objetivos, é essencial que o designer participe de todas as etapas do processo projetual, desde os requisitos iniciais, idealização de conceitos, seleção de materiais, e processos de produção e etapas pós-produção. Esse profissional deverá ser capaz de perceber como o resultado do seu trabalho é capaz de influenciar os padrões de consumo atuais, dispondo ideias e soluções mais sustentáveis. Esse contexto social atual requer dos governos, organizações e instituições, entre tantos outros fatores, novos métodos para projetar e gerenciar processos, organizar e compartilhar competências, conduzir pesquisas, projetar sistemas e novos posicionamentos com relação aos processos de ensino-aprendizagem. O surgimento de teorias coerentes sobre a evolução do pensamento em design auxilia para que se percebam novas maneiras para ensinar, praticar e compartilhar o design.

Mesmo compreendendo que para inovar é necessário romper barreiras culturais e orçamentárias, é importante que os designers, fabricantes, importadores, distribuidores, comerciantes e consumidores invistam para colocar no mercado produtos que sejam amigos do meio ambiente, diminuindo a quantidade de resíduos descartados incorretamente e, norteando a transformação consciente e prudente rumo a uma sociedade mais sustentável de fato. As inovações tendem a expandir mercados, tornando os produtos mais rentáveis e as empresas mais competitivas.

Como as questões sustentáveis estão em pleno desenvolvimento e ascensão (evidenciado por esse estudo bibliométrico), os produtos que refletirem essas preocupações possivelmente terão um espaço maior no mercado, e as empresas que se valerem dessa prática poderão ter uma ótima forma de se comunicar com seus consumidores. Um produto inovador pode ajudar na conquista dos disputados espaços nos pontos de venda.

Para que se consiga alcançar níveis razoáveis de sustentabilidade e qualidade de vida no Brasil, se faz necessário uma revisão no comportamento econômico social. É urgente que a sociedade passe a 
adotar atitudes que resultem na redução de impactos negativos. Não jogar lixo nas vias públicas, nos rios, mares e parques, assim como deixar em casa o automóvel alguns dias da semana, são pequenos exemplos de atitudes individuais que podem contribuir na coletividade. Quanto ao comportamento econômico da sociedade, implica numa mudança de atitude em relação ao consumo: é preciso mais informações sobre a procedência dos objetos utilizados, a maneira como foram produzidos e por quem fora fabricado. Algumas vezes, por trás de um objeto de grife ou uma roupa de marca conceituada, esconde-se a dura realidade de exploração de mão de obra infantil, poluição ambiental criminosa ou outros desrespeitos aos seres humanos, a vida e ao planeta.

Mudanças estas que somente poderão ser percebidas quando todos tomarem consciência de seus atos e de seus comportamentos, percebendo que o que fizermos no nosso ambiente, influencia o ambiente de outros seres. Cada área é responsável por sua contribuição, e pode ser por meio da introdução dos conceitos do design (focados em práticas sustentáveis) nos setores administrativos e estratégicos, que as indústrias e organizações possam buscar soluções para os problemas ambientais que enfrentamos na atualidade, incentivando o fortalecimento de uma cultura de inovação sustentável.

\section{REFERÊNCIAS}

ARAÚJO, C. A. Bibliometria: evolução histórica e questões atuais. Em Questão, Porto Alegre, v. 12, n1, p. 11-13, 2006.

BARROS, I. S. O luxo do Lixo: eco design uma nova perspectiva para a indústria da moda. São Paulo, SP: Atlas, 2010.

BAUMAN, Z. Capitalismo parasitário. Tradução para o português de Eliana Aguiar. Rio de Janeiro: Zahar, 2010.

. Modernidade Líquida. Rio de Janeiro: J. Zahar, 2001.

Zahar, 2009

Vida líquida. Tradução para o português de Carlos Alberto Medeiros. 2. ed. Rio de Janeiro:

BARBIERI, J. C. Gestão Ambiental Empresarial: conceitos, modelos e instrumentos. São Paulo: Saraiva, 2004.

BECK, U. “A Reinvenção da Política: Rumo a uma Teoria da Modernização Reflexiva”. In: BECK, U.; GIDDENS, A.; LASH, S. Modernização Reflexiva. São Paulo: Editora UNESP, 1997.

BOSSELMANN, K. The principle of sustainability: transforming Law and governance. Surrey, England: Ashgate Publishing Limited, 2009.

CAMARGO, A. L. d. B. Desenvolvimento Sustentável: dimensões e desafios. Campinas, SP: Papirus, 2003.

CARDOSO, R. Design para um mundo complexo. São Paulo: Cosac Naify, 2013.

Uma introdução à história do design. São Paulo: Blucher, 2008.

CHICK, A.; MICKLETHWAITE, P. Design for Sustainable Change: How Design and Designer can drive the sustainability agenda. UK: AVA Publishing Ltd., 2011.

COLÓQUI DE MODA. Saiba Mais. $13^{\circ}$ Colóquio de Moda. 2017. Disponível em:

<http://www.coloquiomoda.com.br/evento.php>. Acesso em: 20 abr. 2017. 
DIAMOND, J. Collapse: how societies choose to fail or succeed. New York: Penguin, 2011.

FORTY, A. Objetos de Desejo: design e sociedade desde 1750. São Paulo: Cosac Naify, 2007.

FRY, T. Design as politics. New York, NY: Berg, 2011.

GIDDENS, A. A Vida em uma Sociedade Pós-Tradicional. In: BECK, U.; GIDDENS, A; LASH, S. Modernização Reflexiva. São Paulo: Editora da Universidade Estadual Paulista, 1997.

JONAS, H. El principio Del responsabilidad: ensayo de una ética para La civilizacion tecnológica. Barcelona: Harder, 1995.

LAZZAROTTI, F.; DALFOVO, M. S.; HOFF, V. E. A bibliometric study of innovation based on Schumpeter. Journal of Technology Management \& Innovation, Santiago, v. 6, n.4. 2011.

MANZINI, É. Design para a inovação social e sustentabilidade: Comunidades criativas, organizações colaborativas e novas redes projetuais. Rio de Janeiro: E-papers, 2008.

MANZINI, É; VEZZOLI, C. O desenvolvimento de produtos sustentáveis: os requisitos ambientais dos produtos industriais. São Paulo: EDUSP, 2002.

MARGOLIN, V. Design Discourse. Chicago, EUA: The University of Chicago Press, 1989.

MARIOTTI, H. Complexidade e Sustentabilidade: o que pode e o que não se pode fazer. São Paulo, Atlas, 2013.

MEDINA, N. M.; SANTOS, E. d. C. Educação Ambiental: uma metodologia participativa de formação. Petrópolis, RJ: Vozes, 2000.

PAPANEK, V. Arquitetura e Design: ecologia e ética. Lisboa, Portugal: 70, 1997.

. Design for the real world. New York: Pantheon, 1971.

VEIGA, J. E. A desgovernança mundial da sustentabilidade. São Paulo: Editora 34, 2013.

. A emergência socioambiental. São Paulo: Senac, 2007.

VEZZOLI, C. Design de sistemas para a sustentabilidade: teoria, métodos e ferramentas para o design sustentável de "sistemas de satisfação". Salvador: EDUFBA, 2010. 